\title{
WHAT DO PATIENTS WANT TO HAPPEN TO THEIR DENTURES BEFORE SURGERY?
}

\author{
M Wood, Recovery Nurse \\ Westmorland General Hospital
}

\section{INTRODUCTION}

The removal of dentures before having an anaesthetic can be an undignified and distressing event. There has been a gradual change in practice and dentures are now often left in place during an anaesthetic. This enquiry into patients' preferences was carried out to find out what patients would like to happen to their dentures, and to see if there were any differences in opinions among age groups. A postal questionnaire was sent out to patients who wore dentures following discharge after surgery. One hundred replies were analysed. There was a spread of opinion across the age groups and by gender. Nurses need to allow patients the choice of what to do in relation to their dentures when going to theatre, although the anaesthetist must make the final decision of whether or not to remove them immediately before the anaesthetic if they feel patient safety could be compromised.

\section{BACKGROUND}

The National Service Framework for Older People ${ }^{(1)}$ aims to root out age discrimination and enable older people to make choices about their care and therefore to be treated as individuals. This should also apply to each stage of preparation for theatre, including what happens to people's dentures preanaesthesia.

In 1998, 12\% of adults in England and Northern Ireland did not have their own teeth and $16 \%$ wore partial dentures ${ }^{(2)}$. The image of the toothless old person as depicted by William Shakespeare in the 'Seven ages of man' as 'sans teeth . sans everything' (As You Like It, 2,7,139-167) has been used throughout the ages to represent the stereotypical 'geriatric'.

Historically, patients were asked to remove their dentures and put them in a pot on their locker before leaving the ward to go to theatre for surgery. There has been a gradual change in practice and custom in recent years following a greater emphasis on individualised care; however, much of the evidence as to what patients want and feel about the issue is anecdotal. I therefore decided to look at the issue of removing dentures by asking patients what their preferences were and comparing the different age groups to see if there is a difference in attitude towards removal of dentures.

Since the advent of the laryngeal mask, many anaesthetists now leave dentures in place throughout the anaesthetic episode as the dentures help to stabilise and maintain the position of the mask ${ }^{(3)}$. In my experience, some anaesthetists prefer to remove dentures if they are going to intubate, as they feel that dentures pose a risk to the maintenance of the airway during anaesthesia. This does not, however, prevent the patient coming to theatre with their dentures in place and having them removed in the anaesthetic room.

There is contradictory advice in the nursing literature. Dyke ${ }^{(4)}$ considers the practice of removing dentures to be unnecessary and cites the problems associated with communication as a reason for leaving dentures in place. Simpson ${ }^{(5)}$, however, states that 'dentures must be removed before surgery' but gives no clear rationale for this point of view. Dawson $^{(6)}$ suggests that the removal of dentures can distort patients' body image, so they should be left in place until the person has arrived in the anaesthetic room where the dentures can be removed in private and then replaced as soon as consciousness returns.

Xavier $^{(7)}$ points out that the patient has often been wearing dentures for many years and has become skilled in manipulating them within his/her mouth. This means that patients can manoeuvre their dentures into the correct place even when very sleepy, so if dentures come out with the laryngeal mask they can quickly and safely be put back in position. In my experience, more patients are coming to theatre with their dentures still in their mouths.

\section{REASONS FOR THE STUDY}

One of the eight key aspects of care used in the clinical benchmarking government document 'The essence of care' ${ }^{\text {(8) }}$ concerns the privacy and dignity of patients. This is a particular issue when a person becomes a patient and is brought to theatre for an anaesthetic.

The dictionary definition of 'dignity' is the state or quality of being worthy of honour. Ward and Morris ${ }^{(9)}$ describe dignity as 'a reflection of people's perception of their worth and self-respect'. Dignity is a feeling, a behaviour and a value judgement; a person can have dignity, a person can be treated with dignity or dignity can be given to someone ${ }^{(10)}$.

Clinical benchmarking emphasises the need to promote privacy, respect for an individual's values, and to ensure that good communication takes place. The ability to communicate well is important both in the anaesthetic room and in the recovery unit. When a person's dentures have been removed it is very difficult for that person to enunciate. Parker ${ }^{\prime \prime \prime}$ comments on the embarrassment that can be felt by edentulous older people when they are trying to reply to questions asked in the anaesthetic room. They may be too embarrassed to speak and may do so only with their hand over their mouth ${ }^{(4)}$, thus creating the possibility of the information that we gather from these patients being inaccurate.

The health service is now required to be more responsive to what patients want. According to the Department of 
Health $^{(12)}$ 'the views and experiences of patients are vital indicators of and contributors to service quality'. I therefore undertook a survey to discover what patients would like to happen to their dentures during an anaesthetic if they were given a choice, and whether there was a difference in opinion between older and younger age groups.

\section{LITERATURE REVIEW}

A search of Medline (January 1996-March 2002) and Cinahl (January 1982-March 2002) was carried out using the words 'dentures' and 'anaesthesia'. Little evidence was found in the literature on the subject of wearing dentures to theatre. However, two articles did examine the wearing of dentures during anaesthesia.

The first related to an incident in Singapore where a patient who was not wearing dentures suffered extreme swelling of the tongue during the recovery period from anaesthesia which was resolved when the dentures were replaced ${ }^{(13)}$. The authors felt that the reason for this was that edentulous patients have been shown to have reduced oral cavity volumes. When dentures are removed the tongue can become compressed and swollen, risking the blocking of the airway. Liu et al recommended that if dentures are removed before anaesthesia, then they should be kept near to hand in case there is a similar emergency.

The second article from the search concerned the rate of infection found in the mouths of 50 patients preoperatively before elective abdominal aortic surgery ${ }^{(14)}$. The authors established that $82 \%$ of the patients had some form of oral infection. Seventy-four per cent wore some form of dentures, of which $45 \%$ were ill-fitting. The authors felt that this presented an infection risk to the prosthesis being implanted.

The indexes of surgical and anaesthetic textbooks in the local hospital library were perused for reference to dentures. Simpson ${ }^{(5)}$ states that dentures should be removed before going to theatre. Smith ${ }^{(15)}$ comments on patients' concerns about the loss of dignity, embarrassment, and disturbed body image following the removal of their dentures, while Dawson $^{(6)}$ states that patients should be aware that their dentures can be worn to theatre but may well be removed in the anaesthetic room. Parker ${ }^{(1)}$, when writing about the perioperative care of the older patient, suggests that policies should ensure that all patients are able to come to theatre with their dentures in place.

The British Dental Health Foundation (BDHF) recommends that patients should keep their dentures in at night to allow the gums to adjust when they first get them unless advised to the contrary by their dentists for oral health reasons ${ }^{(16)}$. Patients who usually remove their dentures to sleep may be more amenable to removing them before going to theatre. Those who are used to sleeping with dentures may find it a strange sensation on waking without their dentures. However, the NHS Direct website (http://www.nhsdirect.co.uk) suggests that people remove their dentures at night to allow the gums to rest, thus demonstrating that there is disagreement among health professionals regarding the care of dentures.

\section{METHOD}

The methodology used for the study was a simple postal questionnaire sent out following patients' discharge from hospital. The questionnaires were sent to the patients after they had been discharged. This was to avoid a conflict between the motive behind the questionnaire and the current hospital practices. Patients who came to theatre and had dentures were identified in recovery and an address label was kept. No other criteria apart from having dentures were applied. The names and addresses were sent to the clinical audit department each week and a postal questionnaire with a prepaid envelope was sent to each patient.

Following discussion with the trust research and development nurse, ethical approval was not sought, as the study had no effect on the care given, was non-experimental and was more in the form of a satisfaction survey than a research project.

The questionnaire was kept as straightforward as possible, asking age, gender, whether the denture was top or bottom, or whether the patient had partial or a full set of dentures. The patients were then asked whether they normally removed their dentures at night and if they routinely used adhesive. Adhesive is recommended by the BDHF if the dentures are loose or are a poor fit - this may have safety implications during anaesthesia as it may be difficult to remove the dentures in an emergency, or if they are loose or poorly fitting they may become a hazard to the airway. The patients were then given a choice of what they would prefer to happen in relation to their dentures:

a to remove them before coming to theatre, leaving them on the locker beside their bed

b wear them to theatre but remove them in the anaesthetic room, and the ward nurse take them back to their locker

c remove the dentures in the anaesthetic room, and then have them replaced when they are in recovery

d keep them in at all times providing it was safe so to do.

There was a space at the bottom of the form for any comments the respondents wished to make. It was decided at the beginning to use a sample of 100 patients to allow ease of analysis. The questionnaires were therefore sent out until 100 replies had been received. The results were scanned by the clinical audit department and then analysed by age, gender, patients' choice of what to do with their dentures, and their normal bedtime practices.

\section{RESULTS}

Fifty-four per cent of the respondents were female, $41 \%$ were male and $5 \%$ did not answer; $27 \%$ were over seventy-five years old, and $27 \%$ were between the ages of 65 years and 75 years (Figure 1).

Fifty-seven per cent had total dentures. Forty-nine per cent of the respondents never remove their dentures at night, but only 13 patients out of the 25 who always remove their dentures at night wished to remove them before going to theatre.

In the under-65 age group, 12 (27\% of age group; two patients did not answer) wanted to remove their dentures and leave them on the ward while $22(50 \%$; two patients did not answer) wanted to wear them all the time. In the over-75-year age group, 11 people $(41 \%)$ wished to remove their dentures before coming to theatre and seven (26\%) wanted to keep them in throughout the operation (Figure 2). There was diversity in opinion showing that the desire to remove dentures before going to theatre is very individual and is not dictated by age, gender or usual sleeping practice. 


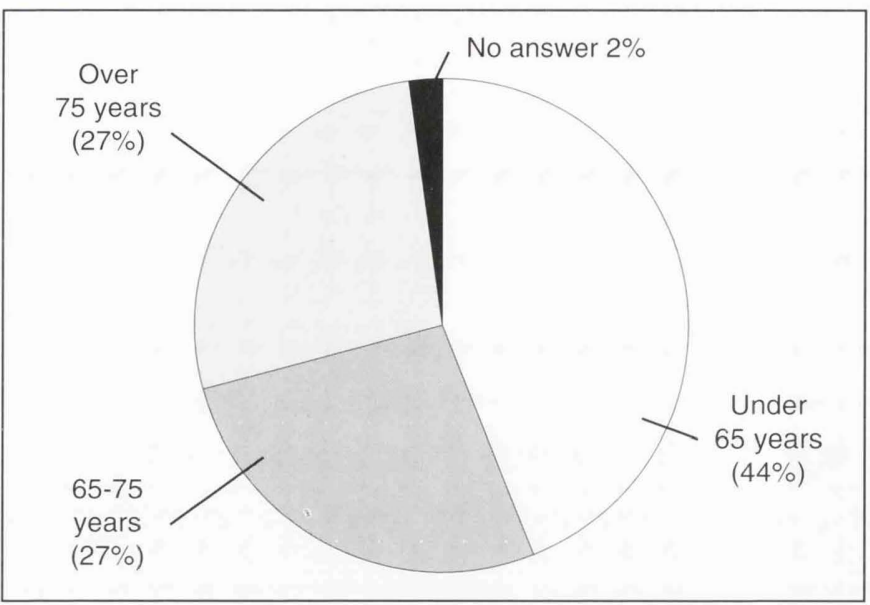

Figure 1

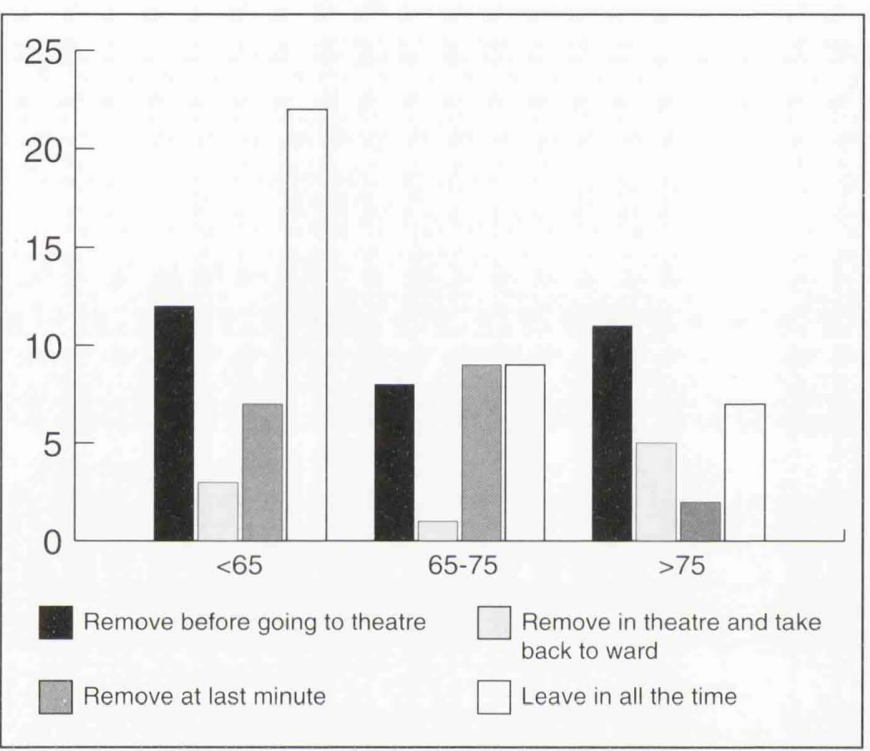

Figure 2

In total, $37 \%$ of people added a comment, $11 \%$ of which were messages of gratitude to the staff for the care that they had received during their stay in hospital. Four per cent of people used the comment box to describe in detail what they normally did with their dentures at night, while $14 \%$ explained what had happened on their recent visit to theatre.

There was some concern about the prospect of damage or loss of dentures, as expressed by one patient: "It made sense to leave any dentures on the ward, then this ensures no misplacement going to theatre."

Some showed the fear and embarrassment felt at the possibility of having to remove their dentures. For example: "The biggest fear with dentures is going into hospital and having to take them out before going into theatre and seeing anyone."

Both of these comments came from people in the under- 65 age group. In the 65-75 age group, comments included: "Having been to theatre many times, I always ask the anaesthetist if I should remove my teeth. The answer is always that it makes no difference so I leave my teeth in."

and

"I change my dentures every night with an old set, as I do not like to be without any at all. I hope this helps you to understand that some patients are different."
The comments from the over-75-year-olds also showed diversity in opinion: "I think this is a minor problem. I am sure that it is more important that you have your treatment."

And

"I was pleased to be able to wear my dentures during my operation because I feel very self-conscious when I do not have them in and do not like people to see me without them."

\section{DISCUSSION AND IMPLICATIONS FOR PRACTICE}

There has been a shift over recent years in health care, from the paternalistic attitude dictating what patients must do with little regard to their personal dignity and individualism, to asking each person what he/she would like to do and enabling that to happen without compromising safety. Dawson promotes the concept of partnership where decision-making is shared, based on scientific evidence, patient preference and clinical effectiveness ${ }^{(6)}$.

In this study, patients showed, in both their answers and their comments, that there is diversity in attitudes towards the removal of dentures. This variation cannot be ascribed to age or gender. Some patients found it very distressing that they might be seen without their dentures, while others were far more concerned about the implications of having an anaesthetic and surgery.

Hibbert suggests that as nurses we should be looking at our preoperative practices to find ways to reduce patients' stress ${ }^{(17)}$. For the patients who wear dentures, providing them with a choice as to whether they wear their dentures to theatre or leave them in the ward may help to alleviate some of their anxiety about the theatre experience.

This survey was simple to administer with little overheads in terms of time or cost. It was limited because of its small sample size (100 respondents) but it did produce interesting comments and results. The results can only be taken as an indication of patients' wishes and thoughts, although it is to be hoped that they will stimulate reflection on the topic.

If patients are going to be given the choice of whether or not to wear dentures to theatre, we must be sure that they are aware of the risk of loss or damage and of the safety issues. The implications for practice that need to be considered are:

- does there need to be written consent or a disclaimer for potential loss or damage?

- is there an adequate supply of denture pots in the anaesthetic room?

- is there an easy way to label the pot?

- has the anaesthetist been reminded that the dentures are in or out?

- do the recovery nurses know that the dentures are still in?

- is there a recognised and failsafe practice for ensuring that dentures removed are taken to recovery for return to the mouth of the correct patient?

The responsibility for safety when leaving the dentures in during anaesthetic needs to remain with the person carrying out the anaesthetic and it must therefore be his/her decision and preference as to whether or not the dentures are removed; this decision needs to be made on sound evidence and not tradition. 


\section{CONCLUSION}

This postal questionnaire was a simple and cost-effective way of finding out what patients think. There was a spread of opinion across the ages about what patients would like to happen to their dentures. Many patients offered additional information to try to help us to understand their habits and feelings on the subject, although two did comment that they thought it was a waste of NHS resources.

The care of dentures during anaesthesia has created anxiety in many patients ${ }^{(18)}$. Nurses need to ensure that the dignity of all patients from all age groups is preserved. There are some patients who do not wish to be seen without their dentures by anyone including family, anaesthetists, anaesthetic nurses or recovery staff, and there are others who fear any damage to or loss of their dentures. Ward staff have the opportunity to offer patients these options on the ward during the preparation for theatre.

Acknowledgements: The author would like to thank Andrew Severn and Marie Kane for their help in the preparation of this article.

\section{REFERENCES}

1 National Service Framework for Older People. Department of Health, London. 2001

2 Adult Dental Health Survey: Oral Health in the United Kingdom 1998. The Stationary Office, London. 1998

3 Brimacombe J, Brain A, Berry A. The laryngeal mask airway instruction manual. 3rd ed. Intravent Orthofix, Maidenhead. 1996

4 Dyke M. Perioperative communication. In: Hind M, Wicker $\mathrm{P}$ (eds) Principles of perioperative practice. Churchill Livingstone, London. 2000. pp66-76

5 Simpson P. Introduction to surgical nursing. In: Simpson P (ed). Introduction to surgical nursing. Arnold, London. 1998. p13
6 Dawson S. Principles of preoperative preparation. In: Manley K, Bellman L (eds) Surgical nursing. Churchill Livingstone, London. 2000. pp386-407

7 Xavier G. The importance of mouth care in preventing infection. Nurs Stand 2000;14(18):47-51

8 The essence of care. Department of Health, London. 2001

9 Ward K, Morris D. Principles of postoperative care. In: Manley K, Bellman L (eds). Surgical Nursing. Churchill Livingstone, London. 2000. pp423-45

10 Haddock J. Towards further clarification of the concept of 'dignity'. J Adv Nurs 1996;24:924-31

11 Parker A. Care of the older perioperative patient. Br J Anaesth Recovery Nurs 2002;3(1):16-20

12 A First Class Service. Department of Health, London. 1998

13 Liu E, Tan W, Pua H. Acute tongue swelling in an edentulous patient relieved by denture insertion. Can J Anaesth 2000;47(11):1151-2

14 Hayrinen-Immonen R, Ikonen T, Lepantalo M, Lindgren $\mathrm{L}$, Lindquist $\mathrm{C}$. Oral health of patients scheduled for elective abdominal aortic correction with prosthesis. Eur J Vasc Endovasc Surg 2000;19(3):294-8

15 Smith D. Perioperative care. In: Pudner R (ed). Nursing the surgical patient. Balliere Tindall, London. 2000. pp3-27

16 British Dental Health Foundation. Tell me about? Dentures. BDHF, Rugby, Warwickshire. 2002

17 Hibbert A. Stress in surgical patients: a physiological perspective. In: Manley K, Bellman L (eds). Surgical nursing. Churchill Livingstone, London. 2000. pp153-167

18 Cobley M, Dunne J, Sanders L. Stressful preoperative preparation procedures. Anaesth 1991;46(12):1019-22 